\title{
Advanced glycation endproducts inhibit prostacyclin production and induce plasminogen activator inhibitor-1 in human microvascular endothelial cells
}

\author{
S. Yamagishi, H. Fujimori, H. Yonekura, Y. Yamamoto, H. Yamamoto \\ Department of Biochemistry, Kanazawa University School of Medicine, Kanazawa, Japan
}

\begin{abstract}
Summary Several thrombogenic abnormalities are associated with diabetes. To investigate the underlying molecular mechanisms, we examined the effects of advanced glycation endproducts (AGE), non-enzymatically glycated protein derivatives, on the production of prostacyclin $\left(\mathrm{PGI}_{2}\right)$, an anti-thrombogenic prostanoid, and of plasminogen activator inhibitor-1 (PAI-1), a fast-acting serine protease inhibitor of fibrinolysis, in human microvascular endothelial cells (EC). Firstly, AGE-bovine serum albumin (BSA) but not non-glycated BSA, was found to considerably decrease the production of $\mathrm{PGI}_{2}$ to about two-thirds of the control value. Secondly, quantitative reverse transcription-polymerase chain reaction showed that AGE-BSA increased the EC levels of mRNA coding for PAI-1, this being associated with a concomitant increase in the immunoreactive PAI-1 contents and the anti-fibrinolytic activity. Thirdly, the effects of AGE on $\mathrm{PGI}_{2}$ and PAI-1 syntheses in EC were found to be
\end{abstract}

mediated by a receptor for AGE (RAGE) because antisense DNA against RAGE mRNA could reverse the AGE effects. Further, it was found that AGE decreased the intracellular cyclic AMP concentrations in EC and that cyclic AMP agonists such as dibutyryl cyclic AMP, forskolin and $\mathrm{PGI}_{2}$ analogue reduced the AGE-stimulated PAI-1 production, suggesting the involvement of cyclic AMP in the AGE-signalling pathway. The results thus suggest that AGE have the ability to cause platelet aggregation and fibrin stabilization, resulting in a predisposition to thrombogenesis and thereby contributing to the development and progression of diabetic vascular complications. [Diabetologia (1998) 41: 1435-1441]

Keywords Advanced glycation endproducts, plasminogen activator inhibitor-1, endothelial cells, microangiopathy, thrombogenesis.
Accelerated atherosclerosis and microvascular complications are perhaps the leading cause of coronary heart disease, blindness and renal failure

Received: 11 November 1997 and in final revised form: 17 July 1998

Corresponding author: Dr. H. Yamamoto, Department of Biochemistry, Kanazawa University School of Medicine, 13-1 Takara-machi, Kanazawa 920-8640, Japan

Abbreviations: PAI-1, Plasminogen activator inhibitor-1; AGE, advanced glycation endproducts; EC, endothelial cells; $\mathrm{PGI}_{2}$, prostacyclin; RAGE, receptor for AGE; BSA, bovine serum albumin; u-PA, urokinase-plasminogen activator; 6keto-PGF $\mathrm{PG}_{1 \alpha}, 6$-keto-prostaglandin $\mathrm{F}_{1 \alpha}$; RT-PCR, reverse transcription-polymerase chain reaction; nt, nucleotide(s); t-PA, tissue-plasminogen activator; HUVEC, human umbilical vein endothelial cells; NF- $\varkappa$ B, nuclear factor kappa B. which are common complications in patients with prolonged diabetes [1-3]. Plasminogen activator inhibitor-1 (PAI-1) is an important fast-acting serine protease inhibitor that attenuates fibrinolysis [4]. Epidemiological studies have demonstrated that reduced fibrinolytic activity because of elevated plasma PAI-1 is an important factor in various thrombotic diseases such as deep vein thrombosis, ischaemic heart disease [5-8] and diabetic vascular complications [9-10]. In addition to the attenuated fibrinolytic activity, hypercoagulability and platelet hyperaggregation are also prevalent in diabetic patients, contributing to microthrombus formation in diabetic micro- and macroangiopathies [11]. The molecular mechanisms underlying these thrombogenic abnormalities, however, are not fully understood. 
Glucose can react non-enzymatically with the amino groups of proteins to form reversible Schiff bases and then, Amadori products. These early glycation products undergo further complex reactions and rearrangements to become irreversibly cross-linked, fluorescent protein derivatives termed advanced glycation endproducts (AGE) [12]. The formation and accumulation of AGE in various tissues as well as in plasma have been known to progress at an extremely accelerated rate in diabetes [13].

Our previous co-culture experiments using pericytes and endothelial cells (EC), the cellular constituents of microvessels, have shown that pericytes not only regulate the growth of $\mathrm{EC}$ but also preserve their ability to produce prostacyclin $\left(\mathrm{PGI}_{2}\right)$ [14], an antithrombogenic prostanoid [15]; this could explain why proliferative diabetic retinopathy develops following pericyte loss, the earliest histopathological hallmark in diabetic retinopathy [16-17]. Furthermore, we have recently shown that AGE exert an inhibitory effect on the growth of pericytes through their interaction with a receptor for AGE (RAGE), and have proposed a novel mechanism for pericyte loss [18].

In this study, we examined the direct effects of AGE on $\mathrm{PGI}_{2}$ and PAI-1 production by human microvascular EC. We show for the first time that AGE not only inhibit $\mathrm{PGI}_{2}$ production but also induce functional PAI-1 synthesis in EC, partly through a decrease in intracellular cyclic AMP levels, and discuss a possible mechanism for thrombogenesis in diabetic microangiopathy.

\section{Materials and methods}

Materials. Bovine serum albumin (BSA) was purchased from Boehringer Mannheim GmbH (Mannheim, Germany). Heparin-Sepharose CL-4B was from Pharmacia LKB (Uppsala, Sweden); reverse transcriptase and $\mathrm{T} 4$ polynucleotide kinase were from Takara (Kyoto, Japan); Hybond- $\mathrm{N}^{+}$nylon membrane from Amersham (Buckinghamshire, United Kingdom); $[\gamma$ ${ }^{32}$ P]ATP from DuPont NEN (Boston, Mass., USA); urokinase-plasminogen activator (u-PA) from JCR Pharmaceuticals Co. Ltd. (Kobe, Japan); plasminogen from Bio Pur AG (Bubendorf, Switzerland); D-Val-Leu-Lys $p$-nitroanilide, forskolin and dibutyryl cyclic AMP from Sigma (St. Louis, Mo., USA). PGI $_{2}$ analogue beraprost sodium was a gift from Toray Industries Inc (Tokyo, Japan). Recombinant human RAGE protein and monoclonal antibody against it were kindly donated from Dr. Toshio Doi (Kyoto University Hospital, Japan).

Cells. Subcultivation ratio of EC from human skin microvessels was 1 to 2 and the cells were maintained in E-BM medium supplemented with $5 \%$ fetal bovine serum, $0.4 \%$ bovine brain extracts, $10 \mathrm{ng} / \mathrm{ml}$ human epidermal growth factor and $1 \mu \mathrm{g} / \mathrm{ml}$ hydrocortisone according to the supplier's instructions (Clonetics Corp., San Diego, Calif., USA). Cells at 5 to 10 passages received AGE and other treatments in a medium lacking epidermal growth factor and hydrocortisone when they reached approximately $70 \%$ confluency $\left(\sim 7000\right.$ cells $\left./ \mathrm{cm}^{2}\right)$.
Preparation of $A G E$. AGE were prepared by incubating BSA (fraction $\mathrm{V}$, fatty acid-free, endotoxin-free) with $0.5 \mathrm{~mol} / \mathrm{l} \mathrm{glu}-$ cose at $37^{\circ} \mathrm{C}$ for 6 weeks under sterile conditions as described previously [19]. After unincorporated sugars were removed by dialysis against phosphate-buffered saline, glucose-modified higher-molecular weight materials were purified by heparin-Sepharose CL-4B column chromatography and used as AGE-BSA. Separation of AGE-BSA from non-glycated BSA was confirmed by SDS-PAGE. The concentration of AGEBSA was determined by the method of Bradford [20]. Control non-glycated BSA was incubated under the same conditions except for the absence of glucose.

Measurement of 6-keto-prostaglandin $F_{1 \alpha}\left(6-k e t o-P G F_{1 \alpha}\right)$. 6Keto-PGF $\mathrm{P}_{1 \alpha}$, a stable metabolite of $\mathrm{PGI}_{2}$, released into media was measured with an Amersham enzyme immunoassay system according to the supplier's recommendation.

Primers and probes. Oligonucleotide primers and probes for quantitative reverse transcription-polymerase chain reactions (RT-PCR) were chemically synthesized and purified as described previously [21]. Sequences of the upstream and downstream primers and the internal probe were 5'-ATGGGATTCAAGATTGATGA-3', 5'-TCAGTATAGTTGAACTTGTT-3' and 5'-AGAGAGCCAGATTCATCATCAAT-3' (nucleotides (nt) 379-398, 811-830 and 584-606) for detecting PAI-1 mRNA (22), 5'-ACCACCATCGAGAACCAGCC-3', 5'-AATCAGCTTCACAACAGTCA-3' and 5'-CTGGTTTGCGGCCATCTACA-3' (nt 2494-2513, 4174-4193 and 25142533) for u-PA mRNA [23], 5'-CGAAGGATTTGCTGGGAAGT-3', 5'-TGCGGTTCTTCAGCACGTGG-3' and 5'-TACGAGGACCAGGGCATCAG-3', (nt 245-264, 746-765 and 294-313) for tissue-plasminogen activator (t-PA) mRNA [24]. The primers and probe used for beta-actin mRNA detection were the same as described previously [21].

Quantitative RT-PCR. Poly(A) ${ }^{+}$RNAs were isolated [21] from cells treated for various time periods with or without AGEBSA, and analyzed by RT-PCR as described previously [25]. After the RT-PCR, 6- $\mu$ l aliquots of each reaction mixture were electrophoresed on $2 \%$ agarose gels, and transferred to Hybond- $\mathrm{N}^{+}$nylon membranes, which were then hybridized with the respective ${ }^{32} \mathrm{P}$-end labelled probes [19]. The amounts of poly $(\mathrm{A})^{+}$RNA templates (30 ng) and the numbers for amplification cycles (20 cycles for beta-actin mRNA, 25 cycles for uPA and t-PA mRNAs, 35 cycles for PAI-1 mRNA) were chosen in quantitative ranges where reactions proceeded linearly, which had been determined by plotting signal intensities as functions of the template amounts and the cycle numbers [19]. Signal intensities of hybridized bands were measured by a Fujix BAS 1000 Image analyzer (Fuji Photo Film Co. Ltd., Hamamatsu, Japan).

Measurement of PAI-1. The amounts of immunoreactive PAI-1 released into media were measured by ELISA (Imulyse PAI-1; Biopool, Umeå, Sweden), according to the supplier's recommendation. Since PAI-1 complexed to u-PA or t-PA is scarcely detectable by this method, the values represent free PAI-1 levels [26]. To determine the biological activity of PAI-1, EC were treated with serum-free medium in the presence or absence of $50 \mu \mathrm{g} / \mathrm{ml}$ AGE for $24 \mathrm{~h}$. Then, the conditioned medium was assayed for anti-fibrinolytic activity in the presence of u-PA (3.8 units $/ \mathrm{ml}$ ), $20 \mu \mathrm{g} / \mathrm{ml}$ plasminogen and the chromogenic plasmin substrates $(60 \mu \mathrm{mol} / \mathrm{l} \mathrm{D}$-Val-Leu-Lys $p$-nitroanilide $)$. Substrate hydrolysis was measured from 0 to $240 \mathrm{~min}$ and plasmin generation was estimated as the slope of the line defined by plotting relative absorbance vs time, PAI-1 activity thus being judged by the extent of the inhibition of plasmin generation [27]. 

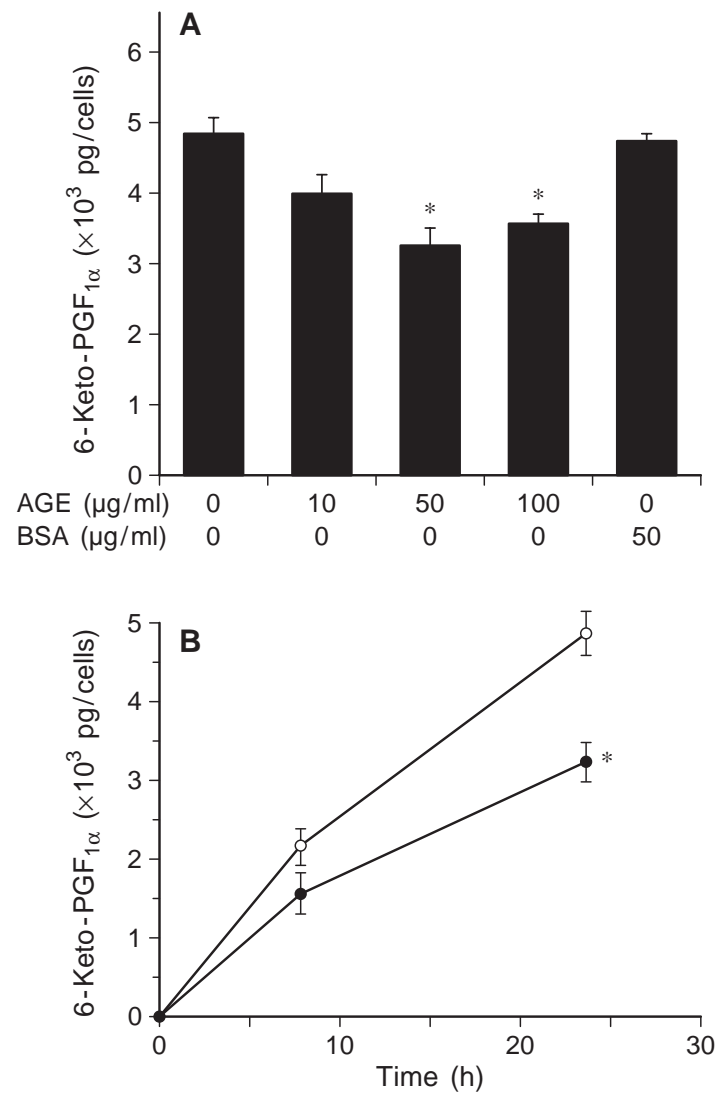

Fig.1. Effects of AGE-BSA on 6-keto-PGF $1 \alpha$ production by human microvascular EC. (A) Dose effects of AGE on 6keto-PGF $_{1 \alpha}$ production by EC. EC were treated with 10,50 or $100 \mu \mathrm{g} / \mathrm{ml} \mathrm{AGE-BSA}$, or $50 \mu \mathrm{g} / \mathrm{ml}$ non-glycated BSA, or without them for $24 \mathrm{~h}$. Each column represents the mean \pm SEM of four replicate experiments. ${ }^{*}, p<0.05$ compared with both the control value without AGE-BSA and that with non-glycated BSA (Mann-Whitney test). (B) Time course of 6-keto$\mathrm{PGF}_{1 \alpha}$ production by EC. EC were treated with $(\bullet)$ or without $50 \mu \mathrm{g} / \mathrm{ml}$ AGE-BSA $(O)$ for the indicated periods of time. Amounts of 6-keto- $\mathrm{PGF}_{1 \alpha}$ released by $\mathrm{EC}$ are indicated on the ordinate. Each point represents the mean \pm SEM of nine replicate experiments. $*, p<0.05$ compared with the control value without AGE-BSA (Mann-Whitney test)

Assay with antisense oligodeoxyribonucleotides. A phosphorothioate antisense complement of human RAGE mRNA, and the corresponding sense oligodeoxyribonucleotide, were synthesized and purified as described previously [28]. Sequences of antisense and sense oligonucleotides were 5'-CAACTGCTGTTCCGGCT-3' and 5'-AGCCGGAACAGCAGTTG-3', respectively, which corresponded to nucleotides 6-22 of human cDNA [28]. The oligonucleotides were added to the medium, with or without $50 \mu \mathrm{g} / \mathrm{ml}$ AGE-BSA, in which EC were grown. After 24 h, 6-keto-PGF ${ }_{1 \alpha}$ and PAI-1 syntheses were assayed.

Western blotting. Subconfluent cultures of EC treated with or without $10 \mu \mathrm{mol} / \mathrm{l}$ oligodeoxyribonucleotides for $24 \mathrm{~h}$ were lysed in phosphate-buffered saline ( $\mathrm{pH} 7.4)$ containing $1 \%$ (V/V) NP-40, $0.5 \%$ (W/V) deoxycholate, $0.1 \%$ (W/V) SDS, $2 \mathrm{mmol} / \mathrm{l}$ phenylmethylsulphonyl fluoride, $1 \mu \mathrm{g} / \mathrm{ml}$ aprotinin, $2 \mathrm{mmol} / \mathrm{l}$ sodium orthovanadate, $10 \mathrm{mmol} / \mathrm{l}$ sodium pyrophosphate, $50 \mathrm{mmol} / 1$ sodium fluoride, $10 \mathrm{mmol} / \mathrm{l}$ EDTA and $1.5 \mathrm{mmol} / 1 \mathrm{MgCl}_{2}$. Fifteen $\mu \mathrm{g}$ of proteins were loaded per lane and separated by SDS-PAGE (12.5\%), and then transferred onto a nitrocellulose membrane. The filter was then treated with a monoclonal antibody against human RAGE, and the resultant immune complexes were visualized with an Amersham enhanced chemiluminescence system as described previously [29].

Measurement of cyclic AMP. EC were treated with or without $50 \mu \mathrm{g} / \mathrm{ml} \mathrm{AGE}$ for $4 \mathrm{~h}$, after which trichloroacetic acid was added to the medium to a final concentration of $5 \%$. Cells were collected, sonicated and centrifuged at $300 \mathrm{~g}$ for $15 \mathrm{~min}$ at $4{ }^{\circ} \mathrm{C}$, and the supernantant saved was then extracted with water-saturated ether to remove the trichloroacetic acid. The resultant aqueous layer was dried by a centrifugal vaporizer, and assayed for cyclic AMP levels with an Amersham enzyme immunoassay system according to the supplier's recommendation.

\section{Results}

AGE inhibition of $\mathrm{PGI}_{2}$ production by microvascular $E C$. $\mathrm{PGI}_{2}$ is a vasodilating, antithrombogenic prostanoid mainly produced by EC [15]. We tested the effects of $\mathrm{AGE}$ on $\mathrm{PGI}_{2}$ production in microvascular $\mathrm{EC}$ by measuring its stable metabolite, 6-keto-PGF ${ }_{1 \alpha}$ released into media. As shown in Figure $1 \mathrm{~A}$, the amounts of 6-keto- $\mathrm{PGF}_{1 \alpha}$ released from EC were decreased with increasing concentrations of AGEBSA; the lowest level was noted at $50 \mu \mathrm{g} / \mathrm{ml}$ AGEBSA, about $30 \%$ lower than the control value without AGE or that with non-glycated BSA. The inhibition of $\mathrm{PGI}_{2}$ production began to be observed at $8 \mathrm{~h}$ after the addition of AGE-BSA, and at $24 \mathrm{~h}$ a statistically relevant decrease was achieved (Fig. 1B).

$P A I-1, u-P A$ and $t-P A m R N A$ levels in AGE-exposed $E C$. Both u-PA and t-PA can stimulate the conversion of plasminogen to plasmin, promoting fibrinolysis, while PAI-1 inhibits plasmin generation by forming inactive complexes with u-PA and t-PA or both [4]. To determine whether AGE could affect fibrinolysis, $\operatorname{poly}(\mathrm{A})^{+}$RNAs were isolated from EC, which had been treated with various concentrations of AGEBSA at various times, and assayed for their contents of PAI-1, u-PA and t-PA mRNAs by a quantitative RT-PCR technique. As shown in Figure 2, AGEBSA were found to increase considerably the concentration of PAI-1 mRNA. The PAI-1 mRNA concentration began to increase at $2 \mathrm{~h}$ in the presence of AGE-BSA, and reached a maximum at $8 \mathrm{~h}$ (Fig. 2A); the peak value was about threefold higher than the basal concentration when standardized with the signal intensities of beta-actin mRNA as an internal control. Among the concentrations tested, the maximal effect was observed with $50 \mu \mathrm{g} / \mathrm{ml}$ AGEBSA (Fig. 2B), the same concentration giving the maximal inhibition of $\mathrm{PGI}_{2}$ production (Fig. 1A). Non-glycated BSA induced no change in PAI-1 mRNA concentrations (data not shown). On the other hand, the concentrations of u-PA and t-PA 
A

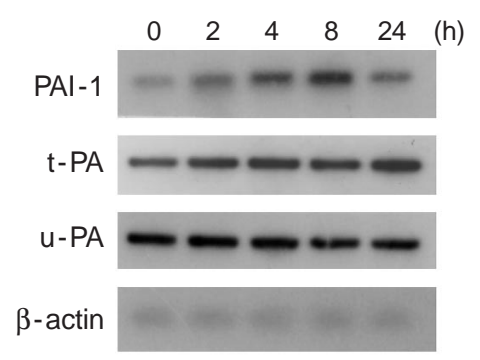

B

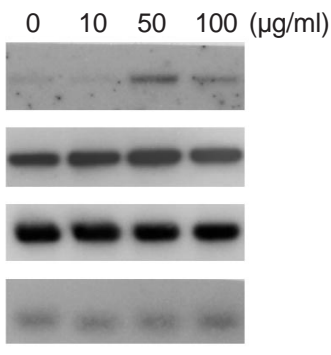

Fig. 2. PAI-1, t-PA and u-PA gene expressions in AGE-exposed EC. (A) Time course of changes in PAI-1, t-PA and uPA mRNA levels. Poly(A) ${ }^{+}$RNAs were isolated from EC treated for the indicated time periods with $50 \mu \mathrm{g} / \mathrm{ml}$ AGEBSA, $30 \mathrm{ng}$ of which were then transcribed and PCR-amplified. (B) Dose response of PAI-1, t-PA and u-PA mRNA concentrations to AGE. After incubation for $4 \mathrm{~h}$ with the indicated concentrations of AGE-BSA, poly $(\mathrm{A})^{+}$RNAs were isolated from EC and $30 \mathrm{ng}$ of them were amplified by RT-PCR. The PCR products were electrophoresed on $2 \%$ agarose gels, transferred onto nylon membranes and hybridized with ${ }^{32} \mathrm{P}$ end labelled probes as described in Materials and methods. PCR amplification for beta-actin mRNA was done for 20 cycles

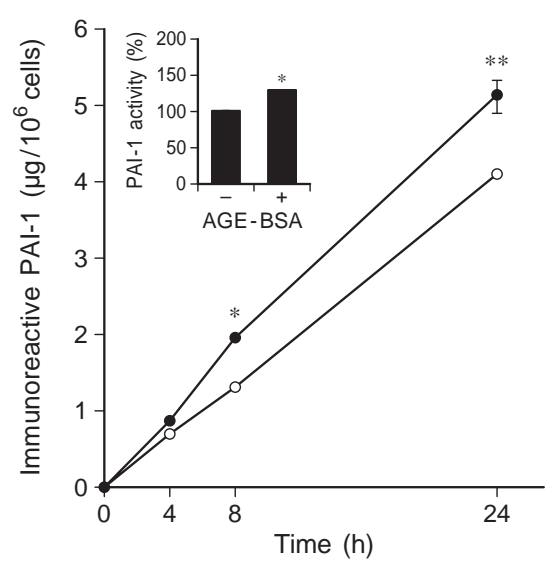

Fig.3. Effects of AGE-BSA on PAI-1 production by human microvascular EC. EC were treated with $(\bullet)$ or without $50 \mu \mathrm{g} / \mathrm{ml}$ AGE-BSA (O) for the indicated time periods. Amounts of PAI-1 antigen released from EC are indicated on the ordinate. Each point represents the mean for six replicate experiments; vertical bars show SEM when larger than the symbol; * and **, $p<0.05$ and $p<0.01$, respectively, compared with the value without AGE-BSA (Mann-Whitney test). Inset, biological assay for PAI-1 activity. Microvascular EC were treated with $(+)$ or without $(-) 50 \mu \mathrm{g} / \mathrm{ml} \mathrm{AGE}$ for $24 \mathrm{~h}$. Conditioned medium was removed and assayed for PAI-1 activity in the presence of $\mathrm{u}-\mathrm{PA}$, plasminogen and the chromogenic plasmin substrates as described in Materials and methods. Data represent the mean \pm SEM of three replicate experiments. $*, p<0.05$ compared with the value without AGE-BSA (Mann-Whitney test)

mRNAs (Fig. 2, A and B) were essentially unchanged by the exposure to AGE-BSA.

$A G E$ induction of functional PAI-1. To confirm whether AGE-BSA increased the synthesis of PAI-1
A

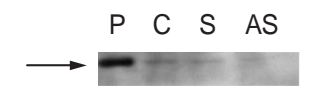

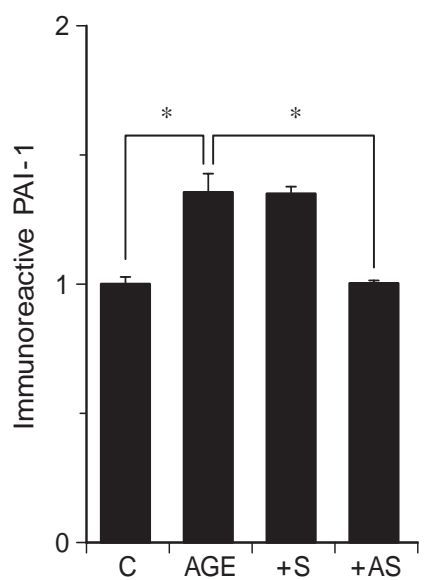

Fig.4. Effects of antisense oligonucleotides on EC. (A) EC were treated with or without $10 \mu \mathrm{mol} / \mathrm{l}$ oligomers for $24 \mathrm{~h}$, and then proteins were extracted and analyzed by Western blotting as described in Materials and methods using a monoclonal antibody against human RAGE. P, human recombinant RAGE protein; C, untreated EC; S, sense oligomer-treated EC; AS, antisense-oligomer-treated EC. Arrow indicates the position of RAGE protein. (B) EC were cultured with $50 \mu \mathrm{g} / \mathrm{ml} \mathrm{AGE}$ in the presence or absence of $10 \mu \mathrm{mol} / \mathrm{l}$ oligomers or without AGE-BSA or oligomers. The relative amounts of 6-keto$\mathrm{PGF}_{1 \alpha}$ and PAI-1 released from EC are indicated on the ordinate, the value without additives being 1. Each column represents the mean value of four replicate experiments. Bars show SEM. * $p<0.05$ compared with the values obtained in the presence of AGE alone (Mann-Whitney test). C, control without additives: AGE, $50 \mu \mathrm{g} / \mathrm{ml}$ AGE-BSA: + S, $50 \mu \mathrm{g} / \mathrm{ml}$ AGEBSA plus $10 \mu \mathrm{mol} / 1$ sense oligomers: + AS, $50 \mu \mathrm{g} / \mathrm{ml}$ AGEBSA plus $10 \mu \mathrm{mol} / \mathrm{l}$ antisense oligomers

proteins, we used ELISA to measure the amounts of PAI-1 antigen released from EC treated with or without AGE-BSA. As shown in Figure 3, immunoreactive PAI-1 was measurably increased by $50 \mu \mathrm{g} / \mathrm{ml}$ AGE; after the 24-h incubation, the value was about $30 \%$ above the control. This correlated strikingly with the anti-fibrinolytic activity of PAI-1 induced by AGE-BSA (Fig. 3 inset).

Reversal of the AGE actions on EC by antisense oligonucleotides against RAGE $m R N A$. We next examined the role of RAGE in the AGE actions. For this, septadecamer antisense oligodeoxyribonucleotides complementary to human RAGE mRNA, and the corresponding sense control, were added to culture media in which EC were grown. As shown in Figure $4 \mathrm{~A}$, Western blot analysis showed that the antisense oligomer but not sense control could inhibit the expression of the RAGE protein in EC. Further, as shown in Figure $4 \mathrm{~B}$, the antisense oligomer was 


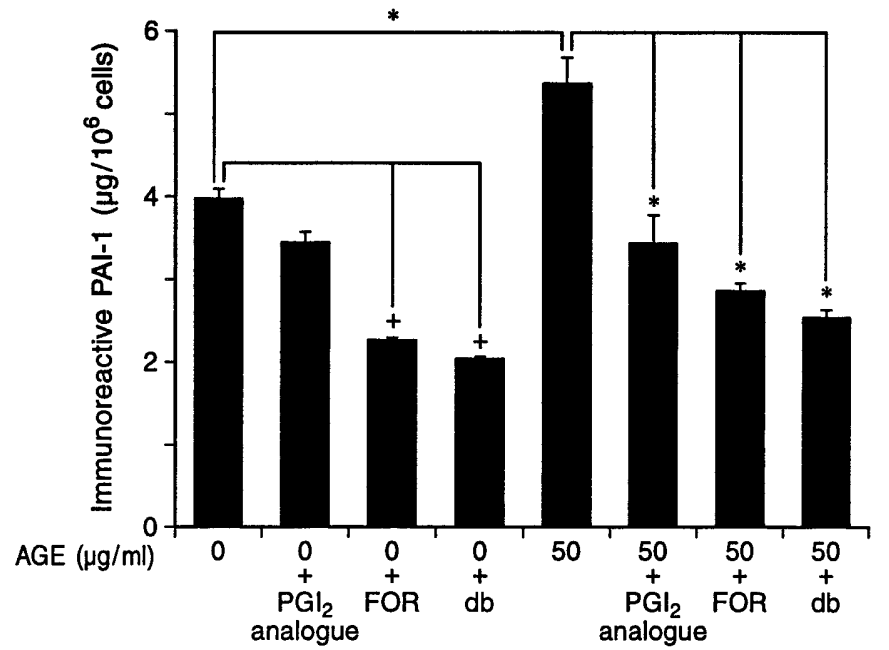

Fig. 5. Effects of cyclic AMP agonists on the AGE-induced PAI-1 production by human microvascular EC. EC were treated with or without $50 \mu \mathrm{g} / \mathrm{ml} \mathrm{AGE-BSA} \mathrm{in} \mathrm{the} \mathrm{presence} \mathrm{or} \mathrm{ab-}$ sence of various types of cyclic AMP agonists for $24 \mathrm{~h}$. Amounts of PAI-1 antigen released by EC are indicated on the ordinate. Each column represents the mean \pm SEM of four replicate experiments. $\mathrm{PGI}_{2}$ analogue, $1 \mu \mathrm{mol} / 1 \mathrm{PGI}_{2}$ analogue; FOR, $10 \mu \mathrm{mol} / \mathrm{l}$ forskolin; db, $1 \mathrm{mmol} / \mathrm{l}$ dibutyryl cyclic AMP.,$+ p<0.05$ compared with the control value without additives, *, $p<0.05$ compared with the value with AGE-BSA alone (Mann-Whitney test)

Table 1. Effects of AGE on cyclic AMP concentrations in microvascular EC

\begin{tabular}{|c|c|}
\hline Treatment & $\begin{array}{l}\text { cyclic AMP concentrations } \\
\left(\mathrm{pmol} / 10^{5} \text { cells }\right)\end{array}$ \\
\hline None $(0 \mathrm{~h})$ & $1.30 \pm 0.09$ \\
\hline None $(4 \mathrm{~h})$ & $1.37 \pm 0.07$ \\
\hline AGE-BSA (4 h) & $0.74 \pm 0.03^{\mathrm{a}}$ \\
\hline AGE-BSA $+\mathrm{PGI}_{2}$ analogue $(4 \mathrm{~h})$ & $1.20 \pm 0.08$ \\
\hline $\mathrm{PGI}_{2}$ analogue $(4 \mathrm{~h})$ & $1.38 \pm 0.08$ \\
\hline
\end{tabular}

Microvascular EC were treated with or without $50 \mu \mathrm{g} / \mathrm{ml} \mathrm{AGE}$ for the indicated time period. After fixation with $5 \%$ trichloroacetic acid solution, cells were collected, sonicated and centrifuged and the resultant supernantant was assayed for cyclic AMP contents as described in Materials and methods. Data represent the mean \pm SEM of nine replicate experiments. ${ }^{a} p<0.05$ compared with the value without additives (MannWhitney test). $\mathrm{PGI}_{2}$ analogue, prostacyclin analogue beraprost sodium added together with AGE-BSA at a concentration of $1 \mu \mathrm{mol} / 1$

found to diminish considerably both the AGE-induced inhibition of $\mathrm{PGI}_{2}$ production and the increase in PAI-1 production by EC.

Reduction by AGE in EC cyclic AMP concentrations and protection against the AGE-induced PAI-1 synthesis by cyclic AMP agonists. Constitutive secretion of PAI-1 is reported to be inhibited by cyclic AMP agonists in human umbilical vein EC (HUVEC) [30]. Accordingly, we tested the effects of AGE on the intracellular cyclic AMP concentrations in micro- vascular EC. As shown in Table 1, $50 \mu \mathrm{g} / \mathrm{ml}$ AGE were found to decrease noticeably the cyclic AMP concentration to about half of the control value. To determine the functional link between the cyclic AMP and PAI-1 levels in EC, we examined the effects of cyclic AMP agonists on the AGE-induced PAI-1 stimulation. As shown in Figure 5, cyclic AMP elevating compounds such as $\mathrm{PGI}_{2}$ analogue beraprost sodium, forskolin and dibutyryl cyclic AMP not only decreased the basal concentration of immunoreactive PAI-1 but also inhibited the AGE induction of this protein in microvascular EC.

\section{Discussion}

In this study we showed for the first time that AGE, non-enzymatically glycated protein derivatives formed at an accelerated rate during hyperglycaemia, could inhibit the production of $\mathrm{PGI}_{2}$ by microvascular EC through interaction with RAGE. This finding extends our previous observation with HUVEC [28], and supports our hypothesis that AGE have thrombogenic activities. Since oxidant stress is reported to inhibit the production of $\mathrm{PGI}_{2}$ in $\mathrm{EC}$ [31], and since vitamin $\mathrm{E}$ treatment can restore the reduction of $\mathrm{PGI}_{2}$ synthesis in diabetic rat aortae [32], the AGERAGE-induced intracellular oxidant stress [33] may account for the impaired $\mathrm{PGI}_{2}$ production by EC.

This study has also showed that AGE could cause the stabilization of preformed fibrin clots. That is, AGE can induce EC expression of the gene for PAI1 , a potent inhibitor of fibrinolysis. As the AGE-induced PAI-1 mRNA upregulation (Fig. 2) coincided with the increase in both the immunoreactive protein and the plasminogen-activator inhibiting activity (Fig. 3), it could be postulated that the de novo synthesis of functional PAI-1 is elicited by AGE. The AGE-induced PAI-1 synthesis was also found to be RAGE-mediated (Fig.4B). Since free radical scavengers such as glutathione are reported to reduce considerably the PAI-1 level in diabetic subjects [34], oxidant stress elicited by AGE-RAGE interaction could also be involved in the PAI-1 overproduction.

Although epidemiological studies have established the plasma PAI-1 elevation in diabetes $[9,10]$, there is no clinical evidence suggesting plasma AGE concentrations as a major contributor to the PAI-1 concentration. Further studies would be required to determine a cause-to-effect relationship between AGE and PAI-1 in diabetic patients, including intervention studies with AGE inhibitors. Geiger et al. $[35,36]$ described that non-enzymatic glycation of lysine residues of plasminogen itself can result in the impaired formation of plasmin. AGE may exert their anti-fibrinolytic activities by plural mechanisms.

The time-response relationship in the two indices was a striking mirror-image (Figs. 1 B and 3), suggest- 
ing that both the AGE-induced $\mathrm{PGI}_{2}$ inhibition and the PAI-1 stimulation could take place simultaneously in EC. Further, the concentration of AGE that gave the maximal effect $(50 \mu \mathrm{g} / \mathrm{ml})$ is the same between the two and is comparable to the concentration of plasma AGE in human diabetic subjects [37]. This would suggest that such ACE-driven thrombogenic and anti-fibrinolytic changes could occur in vivo. Although the AGE effects appeared to be modest, we speculate that chronic exposure to AGE during prolonged hyperglycaemia causes blood vessels to become more susceptible to fibrin formation and stabilization. Actually, a decrease of approximately $30 \%$ in plasma $\mathrm{PGI}_{2}$ was a risk factor for diabetic vascular complications [38], and about a one and one halffold increase in plasma PAI-1 activity resulted in an impaired fibrinolytic capacity in various thrombogenic disorders $[6,8,10]$. In addition, a synergistic involvement of glucose and AGE on reduced fibrinolysis was suggested by Maiello et al. [39] who showed that high glucose increased the PAI-1 activity in HUVEC by approximately $120 \%$.

This study has also shown for the first time that AGE decrease the intracellular cyclic AMP concentration in EC (Table 1), and that cyclic AMP agonists can protect against the AGE-induced increase in the EC production of PAI-1 (Fig.5), indicating that AGE might exert their anti-fibrinolytic activity at least in part through the cyclic AMP reduction. This finding could be important in several respects.

Firstly, it suggests a reciprocal link between $\mathrm{PGI}_{2}$ and PAI-1 productions under the influence of AGE. As $\mathrm{PGI}_{2}$ exerts its biological action through the increase of intracellular cyclic AMP [40], AGE inhibition of $\mathrm{PGI}_{2}$ synthesis would result in further exacerbation of the PAI-1 stimulation. Constitutive and phorbol ester-stimulated expression of PAI-1 in HUVEC is also known to be inhibited by cyclic AMP $[30,41]$.

Secondly, it suggests an involvement of cyclic AMP in the AGE-signalling pathway. The AGERAGE interaction is reported to induce oxidant stress and then to activate nuclear factor kappa B (NF- $x$ B) [42]. Since NF- $x$ B binding sites are identified in the PAI-1 promotor region [43], AGE probably enhanced the transcription of PAI-1 gene through the NF- $x \mathrm{~B}$-mediated pathway. Agonists that increase intracellular cyclic AMP concentrations inhibit the NF- $x \mathrm{~B}$-mediated gene transcription in HUVEC [44]. Accordingly, AGE-induced PAI-1 mRNA upregulation would be enhanced by the decrease in cyclic AMP. An overall scheme for the AGE-induced thrombogenesis would thus seem to be

$\begin{aligned} & \mathrm{AGE} \rightarrow \mathrm{RAGE} \rightarrow \text { oxidant stress } \rightarrow \mathrm{PGI}_{2} \downarrow \longrightarrow \\ & \rightarrow \mathrm{PAI}-1 \uparrow \leftarrow\end{aligned}$ cyclic AMP $\downarrow$.
Thirdly, as shown previously, hypoxia [21] and AGE themselves [19] cause angiogenesis, another hallmark of diabetic microangiopathy, through the induction of autocrine vascular endothelial growth factor in EC. The AGE-driven microthrombus formation would thus give rise to local hypoxia, superdriving angiogenesis and thereby leading to further progression of diabetic microangiopathy.

Fourthly, cyclic AMP agonists such as $\mathrm{PGI}_{2}$ analogue, which ameliorate effectively the thrombogenic effects of AGE (Fig. 5), may have therapeutic potential in the treatment of diabetic vascular complications, the main cause of diminished quality and expectancy of life in patients with diabetes.

Acknowledgements. This study has been supported by "Research for the Future" Program of The Japan Society for the Promotion of Science (H. Yamamoto). We thank S. Matsudaira and R.Kitamura for assistance and B.Bell for reading the manuscript.

\section{References}

1. Kannel WB, McGee DL (1979) Diabetes and cardiovascular disease: the Framingham study. JAMA 241: 2035-2038

2. L'Esperance FA, James WA, Judson PH (1990) The eye and diabetes mellitus. In: Lifkin H, Porte D (eds) Ellenberg and Rifkin's Diabetes Mellitus, Theory and Practice, Elsevier, New York, pp 661-683

3. Friedman EA (1990) Diabetic renal disease. In: Lifkin H, Porte D (eds) Ellenberg and Rifkin's Diabetes Mellitus, Theory and Practice, Elsevier, New York, pp 684-709

4. Egbert KO, Chiên TT, Adriana R, Fedor B (1984) Demonstration of a fast-acting inhibitor of plasminogen activators in human plasma. Blood 64: 907-913

5. Dawson S, Henney A (1992) The status of PAI-1 as a risk factor for arterial and thrombotic disease: A review. Atherosclerosis 95: 105-117

6. Páramo JA, Alfaro MJ, Rocha E (1985) Postoperative changes in the plasmatic levels of tissue-type plasminogen activator and its fast-acting inhibitor-relationship to deep vein thrombosis and influence of prophylaxis. Thrombosis and Hemostasis 54: 713-716

7. Páramo JA, Colucci M, Collen D (1985) Plasminogen activator inhibitor in the blood of patients with coronary artery disease. BMJ 291: 573-574

8. Hamsten A, Faire U, Walldius G et al. (1987) Plasminogen activator inhibitor in plasma: risk factor for recurrent myocardial infarction. Lancet 2: 3-8

9. Small M, Kluft C, MacCuish AC, Lowe GDO (1989) Tissue plasminogen activator inhibition in diabetes mellitus. Diabetes Care 12: 655-658

10. Auwerx J, Bouillon R, Collen D, Geboers J (1989) Tissuetype plasminogen activator antigen and plasminogen activator inhibitor in diabetes mellitus. Atherosclerosis 8: 68-72

11. Brownlee M, Cerami A (1981) The biochemistry of the complications of diabetes mellitus. Annu Rev Biochem 50: 385-432

12. Brownlee M, Cerami A, Vlassara H (1988) Advanced glycosylation end products in tissue and the biochemical basis of diabetic complications. N Engl J Med 318: 1315-1321 
13. Vlassara H (1990) Chronic diabetic complications and tissue glycosylation. Diabetes Care 13 [Suppl.4]: 1180-1185

14. Yamagishi S, Kobayashi K, Yamamoto H (1993) Vascular pericytes not only regulate growth, but also preserve prostacyclin-producing ability and protect against lipid peroxide-induced injury of co-cultured endothelial cells. Biochem Biophys Res Commun 190: 418-425

15. Moncada S, Vane JR (1979) Pharmacology and endogenous roles of prostaglandin endoperoxides, thromboxane $\mathrm{A}_{2}$, and prostacyclin. Pharmacol Rev 30: 293-331

16. Kuwabara T, Kogan DG (1960) Studies on the retinal vascular pattern. I. Normal Architecture. Arch Ophthalmol 64: 904-911

17. Yamagishi S, Hsu CC, Kobayashi K, Yamamoto H (1993) Endothelin 1 mediates endothelial cell-dependent proliferation of vascular pericytes. Biochem Biophys Res Commun 191: 840-846

18. Yamagishi S, Hsu CC, Taniguchi M et al. (1995) Receptormediated toxicity to pericytes of advanced glycosylation end products: A possible mechanism of pericyte loss in diabetic microangiopathy. Biochem Biophys Res Commun 213: 681-687

19. Yamagishi S, Yonekura H, Yamamoto Y et al. (1997) Advanced glycation endproducts-driven angiogenesis in vitro. Induction of the growth and tube formation of human microvascular endothelial cells through autocrine vascular endothelial growth factor. J Biol Chem 272: 8723-8730

20. Bradford M (1976) A rapid and sensitive method for the quantitation of microgram quantities of protein utilizing the principal of protein-dye binding. Anal Biochem 72:248-254

21. Nomura M, Yamagishi S, Harada S et al. (1995) Possible participation of autocrine and paracrine vascular endothelial growth factors in hypoxia-induced proliferation of endothelial cells and pericytes. J Biol Chem 270: 28316-28324

22. Loskutoff D, Linders M, Keijer J, Veerman H, Van Heerikhuizen H, Pannekoek H (1987) Structure of the human plasminogen activator inhibitor 1 gene: Nonrandom distribution of introns. Biochemistry 26: 3763-3768

23. Riccio A, Grimaldi G, Verde P, Sebastio G, Boast S, Blasi F (1985) The human urokinase-plasminogen activator gene and its promotor. Nucleic Acids Res 13: 2759-2771

24. Itagaki Y, Yasuda H, Morinaga T, Mitsuda S, Higashio K (1991) Purification and characterization of tissue plasminogen activator secreted by human embryonic lung diploid fibroblasts, IMR-90 cells. Agric Biol Chem 55: 1225-1232

25. Hatakeyama H, Miyamori I, Fujita T, Takeda Y, Takeda R, Yamamoto H (1994) Vascular aldosterone: Biosynthesis and link to angiotensin II-induced hypertrophy of vascular smooth muscle cells. J Biol Chem 269: 24316-24320

26. Pandolfi A, Iacoviello L, Capani F, Vitacolonna E, Donati MB, Consoli A (1996) Glucose and insulin independently reduce the fibrinolytic potential of human vascular smooth muscle cells in culture. Diabetologia 39: 1425-1431

27. Etingin OR, Hajjar DP, Hajjar KA, Harpel PC, Nachman RL (1991) Lipoprotein (a) regulates plasminogen activator inhibitor-1 expression in endothelial cells. J Biol Chem 266: 2459-2465

28. Yamagishi S, Yamamoto Y, Harada S, Hsu CC, Yamamoto H (1996) Advanced glycosylation end products stimulate the growth but inhibit the prostacyclin-producing ability of endothelial cells through interactions with their receptors. FEBS Lett 384: 103-106

29. Kaji M, Yonemura Y, Harada S, Liu X, Terada I, Yamamoto $\mathrm{H}$ (1996) Participation of c-met in the progression of hu- man gastric cancers: anti-c-met oligonucleotides inhibit proliferation or invasiveness of gastric cancer cells. Cancer Gene Ther 3: 393-404

30. Santell L, Levin EG (1988) Cyclic AMP potentiates phorbol ester stimulation of tissue plasminogen activator release and inhibits secretion of plasminogen activator inhibitor-1 from human endothelial cells. J Biol Chem 263: 16802-16808

31. Whorton AR, Montgomery ME, Kent RS (1985) Effect of hydrogen peroxide on prostaglandin production and cellular integrity in cultured porcine aortic endothelial cells. J Clin Invest 76: 295-302

32. Karpen CW, Pritchard Jr KA, Arnold JH, Cornwell DG, Panganamala RV (1982) Restoration of prostacyclin/thromboxane $A_{2}$ balance in the diabetic rat. Diabetes 31: 947-951

33. Yan SD, Schmidt AM, Anderson GM et al. (1994) Enhanced cellular oxidant stress by the interaction of advanced glycation end products with their receptors/binding proteins. J Biol Chem 269: 9889-9897

34. Martina V, Bruno GA, Pannocchia A et al. (1996) PAI-1 reduction after treatment with glutathione in NIDDM. Fibrinolysis 10 [Supp 2]: 63-65

35. Geiger M, Binder BR (1984) Plasminogen activation in diabetes mellitus. J Biol Chem 259: 2976-2981

36. Geiger M, Binder BR (1986) Nonenzymatic glycosylation as a contributing factor to defective fibrinolysis in diabetes mellitus. Haemostasis 16: 439-446

37. Makita Z, Vlassara H, Cerami A, Bucala R (1992) Immunochemical detection of advanced glycosylation end products in vivo. J Biol Chem 267: 5133-5138

38. Dollery CT, Friedman LA, Hensby CN et al. (1979) Circulating prostacyclin may be reduced in diabetes. Lancet 2: 1365

39. Maiello M, Boeri D, Podesta F et al. (1992) Increased expression of tissue plasminogen activator and its inhibitor and reduced fibrinolytic potential of human endothelial cells cultured in elevated glucose. Diabetes 41: 1009-1015

40. Hopkins NK, Gorman RR (1981) Regulation of endothelial cell cyclic nucleotide metabolism by prostacyclin. J Clin Invest 67: 540-546

41. Kooistra T, Bosma PJ, Toet K et al. (1991) Role of protein kinase $\mathrm{C}$ and cyclic adenosine monophosphate in the regulation of tissue-type plasminogen activator, plasminogen activator inhibitor-1, and platelet-derived growth factor mRNA levels in human endothelial cells. Arteriosclerosis and Thrombosis 11: 1042-1052

42. Wautier JL, Wautier MP, Schmidt AM et al. (1994) Advanced glycation end products (AGEs) on the surface of diabetic erythrocytes bind to the vessel wall via a specific receptor inducing oxidant stress in the vasculature: A link between surface-associated AGEs and diabetic complications. Proc Natl Acad Sci USA 91: 7742-7746

43. Descheemaeker KA, Wyns S, Nelles L, Auwerx J, Ny T, Collen D (1992) Interaction of AP-1-, AP-2-, and SP 1like proteins with two distinct sites in the upstream regulatory region of te plasminogen activator inhibitor-1 gene mediates the phorbol 12-myristate 13-acetate response. J Biol Chem 267: 15086-15091

44. Ollivier V, Parry GCN, Cobb RR, De Prost D, Macjman N (1996) Elevated cyclic AMP inhibits NF- $x$ B-mediated transcription in human monocytic cells and endothelial cells. J Biol Chem 271: 20828-20835 